Patrimonio popular en Cataluña frente a producción musical: un reto para la educación de los adolescentes Adrien Faure-Carvallo, Maria Antonia Pujol i Subira, Josep Gustems-Carnicer y Carolina Martín Piñol Epistemus - Revista de estudios en Música, Cognición y Cultura, 9(1), 80-97, e029, 2021 ISSN 1853-0494 | https://doi.org/10.24215/18530494e029

https://revistas.unlp.edu.ar/Epistemus Sociedad Argentina para las Ciencias Cognitivas de la Música (SACCoM)

\title{
Patrimonio popular en Cataluña frente a producción musical: un reto para la educación de los adolescentes
}

\author{
Adrien Faure-Carvallo', Maria Antonia Pujol i Subira², Josep \\ Gustems-Carnicer ${ }^{3}$ y Carolina Martín Piñol ${ }^{4}$ \\ adrienfaure@ub.edu \\ 1,2,3y ${ }^{4}$ Universidad de Barcelona
}

\section{Resumen}

El patrimonio musical popular forma parte del patrimonio inmaterial y es un factor identitario compartido que debe ser tratado con especial atención en el marco de la educación formal. Este trabajo tiene como objetivo describir los procesos tradicionales de transmisión, transformación y creación compartida que caracterizan al patrimonio musical popular en Cataluña frente a los cambios presentes en las músicas de consumo masivo y plantear posibles modos de abordaje desde la Educación Secundaria Obligatoria. Así mismo, se comentan sus actuales derivas frente a los procesos tecnológicos de la producción musical, propios de las músicas de consumo masivo, que condicionan los modos de escucha de los adolescentes, implicando serias dificultades en la preservación y valoración estética y funcional de dicho patrimonio en el futuro.

\section{Palabras Clave}

Patrimonio musical, música popular, Cataluña, producción musical, educación musical 


\title{
Popular heritage in Catalonia and musical production: a challenge for adolescent education
}

\begin{abstract}
The popular musical heritage is a part of the intangible heritage and a shared identity factor that must be treated with special attention in the framework of formal education. The aim of this work is to describe the traditional processes of transmission, transformation and shared creation that characterise the popular musical heritage in Catalonia in front of the present changes in the music of mass consumption and to propose possible ways of approach from Compulsory Secondary Education. Likewise, its current drifts in front of the technological processes of music production, typical of mass consumption music, which condition the listening modes of adolescents will be discussed, implying serious difficulties in the preservation and aesthetic and functional evaluation of this heritage in the future.
\end{abstract}

\section{Keywords}

Musical heritage, popular music, Catalonia, musical production, music education

\section{Introducción}

Según el currículo de la Educación Secundaria Obligatoria en España-ESO, en adelante-, publicado mediante el Real Decreto 1105/2014 (Ministerio de Educación, Cultura y Deporte, 2015), el "conocer, valorar y respetar los aspectos básicos de la cultura y la historia propias y de los demás, así como el patrimonio artístico y cultural" (p.177) constituyen algunos de los principales objetivos de esta etapa educativa. Además, en el mismo documento se especifica concretamente la necesidad de dar a conocer el valor del patrimonio musical a los estudiantes. Pero, ¿qué entendemos por patrimonio musical? ¿Y cómo debemos abordarlo desde la educación musical? ¿Qué dificultades supone para los adolescentes de hoy día?

El concepto de patrimonio constituye la base fundamental de lo que comúnmente se denominan «bienes culturales». Es ampliamente conocido, sobre todo entre los sectores que se dedican a la conservación del patrimonio, que, en todas las sociedades, estos vestigios constituyen un testimonio elemental del pasado y del presente, y que son básicos para el futuro de las nuevas generaciones; es decir, piezas fundamentales para la comprensión de su historia y su propia identidad cultural. 
En ese contexto, la participación abierta y la voluntad de aprender de sus ciudadanos resultan piezas clave como parte de esta preservación. Es decir, la custodia de estos bienes patrimoniales se basa en la información y la formación del público, condiciones esenciales para su entendimiento. Está claro que una suma ingente de informaciones, un listado de datos o un acopio de objetos materiales sin una organización didáctica y precisa no resultan lo suficientemente ilustrativas. En este sentido, las teorías de Freeman Tilden son fundamentales para la comprensión del concepto «interpretación de patrimonio» (Tilden, 2006). Estas se basan en el axioma de que a mayor educación y entendimiento, existirá más interpretación y, por ende, más conservación. Sam Ham (2007) insiste, además, en la necesidad de que estos comportamientos ocurran de inmediato o en un corto lapso de tiempo posterior a las experiencias vividas.

En definitiva, tal y como la propia Asociación para la Interpretación del Patrimonio (2006) considera, la experiencia cultural debe estructurarse bajo un plan de interpretación construido para que el mensaje final sea óptimo. Para ello hay que tener en cuenta que el patrimonio forma parte de la identidad de una cultura o un territorio, por lo que se puede convertir en una herramienta para mejorar la vida de su población, siempre y cuando se realice una buena gestión. Por lo tanto, tal y como apuntan Santacana y Llonch (2016), los objetos patrimoniales pueden facilitar un testimonio tecnológico, histórico, ideológico o estético, aunque su valor será proporcional al del significado colectivo que se le otorgue y no solamente a su materialidad.

Es importante, además, agregar a esta idea inicial el valor del llamado «patrimonio inmateriabr. Este constituye un bien frágil, complejo y de gran valor para la sociedad que lo conserva, puesto que habita en el intelecto de los individuos (Martín, 2009). El patrimonio musical se puede considerar uno de los más amplios por su composición, dado que es tanto material como inmaterial. Cabe destacar que, por un lado, se tienen en cuenta todos aquellos vestigios materiales que se conservan -véanse música manuscrita, grabaciones, iconografía o instrumentos musicales-y, por otro, la parte inmaterial (UNESCO, 2003). Así, hemos de tener en cuenta que una gran parte del patrimonio existente es intangible, como las músicas de tradición oral transmitidas de generación en generación.

En definitiva, la abundancia del patrimonio musical reside en cada una de las sociedades que conforman la humanidad, y su riqueza, en la variedad que lo constituye. Por ello representa una urgencia y una necesidad salvaguardar el patrimonio musical para las nuevas generaciones en todas sus formas, evidencias experienciales relevantes de cada una de las culturas. Es aquí donde el papel de la educación, las nuevas generaciones y prácticas sociales deviene capital.

Si bien, con el paso del tiempo, se ha podido observar una tendencia general 
en pro de la inclusión de las músicas populares-urbanas en las programaciones de la ESO (Rodríguez, 2004) -persiguiendo un acercamiento motivador de sus objetivos y contenidos a la realidad musical adolescente (Flores, 2007)—, la educación de los jóvenes de hoy en día debe seguir abarcando el repertorio musical en toda su extensión y hacer especial hincapié en el patrimonio musical menos conocido y consumido en la actualidad y, por lo tanto, más frágil y vulnerable. Así, se fomentará la abertura de miras necesaria entre los jóvenes, el conocimiento de otras realidades y el respeto por estas (Giráldez, 1997).

A lo largo de este artículo, iremos viendo esta necesidad tanto de incorporación como de recuperación y conservación del patrimonio musical nuevo y antiguo en el ámbito educativo formal. Esto es de especial interés en la etapa de la adolescencia, donde la identidad se construye, en gran parte, sobre las prácticas sociales del grupo (Faure, Calderón y Gustems, 2020).

\section{Objetivos}

El objetivo de este trabajo es describir los procesos tradicionales de transmisión, transformación y creación compartida que caracterizan al patrimonio musical popular en Cataluña frente a los cambios presentes en las músicas de consumo masivo y plantear posibles modos de abordaje desde la Educación Secundaria Obligatoria.

\section{El patrimonio musical, repetición, interpretación y cocreación: un equilibrio dinámico}

Thuston Dart, en su interesante tratado La interpretación de la música (2002), plantea cómo las artes pueden diferenciarse en (1) aquellas que se crean de una sola vez, para siempre, y (2) las que necesitan una re-creación cada vez que se quieren realizar. Tal sería el caso de la ejecución musical, un fenómeno único que puede ser similar a otras interpretaciones de la misma obra, pero nunca idéntico, o al menos así ha sido en la práctica musical durante siglos: un arte re-creativa o del tiempo ligada a un código (ya sea oral, gestual o escrito) que transmite las intenciones del autor al intérprete, y este, al público oyente. El estudio de este código y de sus reinterpretaciones forma la base en que se sustentan la musicología histórica y la etnomusicología, y es donde situamos la mayor parte de patrimonio musical del pasado (Dart, 2002).

Es cierto que estos códigos musicales son, en muchos sentidos, incompletos y no recogen la intención o las características de aquello que pretenden transmitir o preservar. Durante años, hemos asistido a controversias sobre las interpretacio- 
nes contrastantes de la llamada «música antigua» a manos de intérpretes altamente capacitados, pero con técnicas y argumentos estéticos contrapuestos. Sería el caso de las interpretaciones de J.S. Bach al piano y con criterios técnicos del romanticismo, por poner un ejemplo ampliamente difundido en conservatorios y escenarios. Cuanto más nos alejamos de la presencia viva del autor, de la partitura manuscrita y de sus indicaciones en forma de cartas, consejos o grabaciones de audio, por ejemplo, más imaginativas y arriesgadas devienen las distintas versiones de la misma música del pasado (Mantel, 2010).

En este contexto, la idea de «repetición» se torna fundamental, pues sustenta buena parte del sistema de notación occidental al tratar de preservar mnemotécnicamente todos aquellos elementos esenciales de una obra. Lo repetible merece ser tratado como un objeto atesorable que preservar y transmitir a las nuevas generaciones. La evolución histórica de la notación musical trata de resolver la imposibilidad de recoger, en un código visual estático, el fenómeno volátil y dinámico de la música, un afán donde interviene también cierta capacidad evocadora e imaginativa de los intérpretes (Kivy, 2005).

Como comentábamos, durante siglos, el creador muchas veces ha delegado en otros intérpretes su arte. Esto plantea grados de atrevimiento y libertad diversos, una distinta actitud por parte de los artistas, que guarda relación con la toma de decisiones y un posicionamiento «cuasi-ético», según Mantel (2010). Buena parte de las versiones de una pieza tienen que ver con determinadas características personales de los intérpretes, un estilo específico de co-creación, un filtro a través del cual recibimos inevitablemente el patrimonio musical de otras épocas. Un «tuneado», un «escúchalo a mi modo» que trata de favorecer la comprensión musical del público, alejado generalmente del conocimiento profundo de las obras.

Como símbolo que es, la música y su experiencia deben analizarse desde una óptica que distinga los aspectos denotativos del hecho musical de aquellos connotativos de carácter social, psicológico o personal. Todos ellos están presentes en la ejecución musical, en la apreciación y crítica por parte de los periodistas y divulgadores, así como en la sabia selección y metodología didáctica por parte de los educadores (Gustems, Calderón, Oporto y Ferreira, 2018).

En el caso del patrimonio musical popular, debemos atender a los estudios etnológicos y antropológicos de la música, que destacan dos componentes a la hora de caracterizarlo: su variabilidad y su funcionalidad (Crivillé, 1983). Ambos están presentes en mayor o menor grado en la mayoría de los estilos musicales. La música popular, patrimonio cultural de la mayoría de una comunidad, incluiría para Bartok (1979) tanto las músicas de tradición oral de origen rural («campesinas, en palabras del célebre etnomusicólogo) como las de tinte culto popularesco, actualmente, las músicas populares urbanas. Mientras que el primer 
grupo se mantiene en los límites de la música de tradición oral, este segundo grupo es el que actualmente mueve gran parte del mercado discográfico a nivel mundial, cuyas preferencias y consumo son marcadamente juveniles (Pedrero, Barrios y Medina, 2019). Este divorcio entre música de tradición básicamente oral frente a música de consumo fundamentalmente discográfico sitúa al patrimonio musical popular en una situación delicada y manifiestamente inferior en cuanto a su presencia y difusión entre los adolescentes, poniendo en peligro, de alguna manera, su capacidad para persistir a lo largo del tiempo.

\section{Creadores e intérpretes en la música popular y tradicional catalana}

Observada desde la óptica de la UNESCO (2003) para la salvaguarda del patrimonio inmaterial, la música popular y tradicional respondería directamente a cuatro de sus cinco ámbitos (Carreras y Garcia Petit, 2018):

- Las tradiciones y expresiones orales, incluido el idioma, como vector del patrimonio cultural inmaterial: palabras, frases y expresiones que están presentes y se utilizan en la comunicación oral musical.

- Las artes del espectáculo. Cualquier manifestación pública festiva popular y tradicional aglutina distintas personas para su deleite, asombro y contemplación, ya sean miembros activos haciendo música, o pasivos, escuchándola.

- Los usos sociales, rituales y actos festivos. Cualquier manifestación con costumbres fuertemente vinculadas a una comunidad contribuye a reforzar el sentimiento de pertenecer o ser parte integrante de la misma.

- Las técnicas artesanales y tradicionales, utilizando materiales naturales y tradicionales del entorno. Son un buen ejemplo el trabajo de los luthiers, constructores artesanos de instrumentos populares y tradicionales, muchas veces poco conocidos e incluso anónimos, fuera de su entorno (Arnella, 1994).

En el caso de Cataluña y los territorios de habla catalana, la UNESCO (2020) ha declarado Patrimonio de la Humanidad algunas fiestas populares que incluyen música en sus actos: El Misterio de Elche (en 2001), La Patum de Berga (2005), El Cant de la Sibilla de Mallorca (2010), el flamenco (2010), los Castells (2010), la fiesta de la Mare de Déu de la Salut de Algemesí (2011), las Fallas de Valencia (2016) y las Tamboradas o repiques rituales de tambores (2018).

Las características de repetición, interpretación y co-creación están siempre 
presentes en las músicas populares y tradicionales. Estos tres distintivos ofrecen, cada uno desde su especificidad, aspectos positivos y aspectos negativos. Si bien la repetición, entendida como algo estático, con pocas o nulas variaciones, facilitaría su preservación, también implicaría entender la música popular y tradicional como un fenómeno estático. En cambio, la interpretación implicaría que la música suene en directo, lo que proporcionaría reconocimiento identitario tanto para los músicos como para los oyentes, aunque la encasillara en un momento y lugar concretos. La co-creación propone ir un poco más allá de la misma música popular y tradicional, adaptándose a las necesidades de cada momento.

Además, en el estudio de la música tradicional y popular en Cataluña, podemos considerar tres entornos que, gracias a su dinamismo, contribuyen a mantener vivo este patrimonio: el entorno de discusión, el entorno sonoro y el entorno de aprendizaje. El entorno de discusión abarcaría todos los congresos donde se habla, se explica y se debate acerca de la música popular y tradicional. Integran el entorno sonoro todas aquellas plazas, calles, parques, patios, escenarios, festivales, estudios de grabación, de pueblos y ciudades de Cataluña que posibilitan que la música popular y tradicional catalana suene en directo en su contexto con la funcionalidad que le es propia (Pujol i Subirà, 2017). Los entornos de aprendizaje, a su vez, están formados por el conjunto de situaciones de enseñanza y aprendizaje, desde el autodidactismo hasta los estudios superiores, colofón máximo en cuanto a estudio formal reglado, pasando por toda una gama de modelos informales y no reglados. Esta amplia diversidad de entornos de aprendizaje facilita el estudio de los instrumentos populares y tradicionales, dando cabida a todas las personas con edades, niveles e intereses distintos.

Para ilustrar dichos entornos de aprendizaje, sin describir la retahíla de escuelas existentes y los procesos académico-sociales que han concluido con la publicación de los decretos de las ordenaciones curriculares regladas (Pujol i Subirà, 2017), presentamos como ejemplo la Escola Folk del Pirineu, por ser un entorno con gran afluencia de adolescentes, donde Peláez, su director, explica que:

Se enseñan los instrumentos tradicionales juntamente con algunos no tradicionales, pero utilizando el material musical (canciones, melodias, bailes...) que nos ha dejado nuestra tradición, adaptándolo y releyéndolo con las distintas aportaciones, gustos, necesidades técnicas, coyunturas estéticas... de profesores y alumnos.

El currículo pedagógico de la Escola Folk del Pirineu es abierto y flexible, adaptado a las posibilidades/necesidades del alumnado, al mismo tiempo que potencía la diversión a través de la música y la danza. Sin dejar de lado el rigor en la enseñanza técnica de los instrumentos, la escuela no tiene como finalidad última la formación 
de profesionales de la música, pero si esto ocurre -iy sucede!- que haya alumnos que tienen un interés muy fuerte por el aprendizaje de la música, instrumentos, lenguaje... ponemos especial ahínco para darles las herramientas necesarias para que consigan más nivel técnico y creativo y estén preparados para seguir sus estudios musicales en centros especializados (Peláez, 2014, p. 139).

El patrimonio tradicional y popular permite, además, cierta identificación social de sus miembros, les pone en contacto con su gente, sus costumbres y su tierra, fortaleciendo un sentimiento de pertenencia a toda una comunidad (Martí, 1996). No obstante, y debido a los medios de comunicación y a procesos migratorios de todo tipo, las dinámicas sociales y culturales en entornos urbanos han alcanzado tal magnitud que resulta difícil pronosticar el futuro a medio plazo de algunas de las manifestaciones tradicionales que han sido cruciales en la definición de la cultura catalana.

Para poder continuar fomentando y, al mismo tiempo, mantener el traspaso generacional con un discurso actual, en 2017 se organizó el Fòrum d'Educació i Cultura Popular (VVAA, 2018), con el fin de relacionar experiencias, personas, métodos, ideas, enfoques diferentes, proyectos innovadores, etc. de buenas prácticas en relación con la potenciación desde la educación de la cultura popular.

La educación y la cultura siempre están relacionadas. La cultura popular está muy presente en los distintos ámbitos educativos, tanto en las mismas clases, como en los momentos de ocio escolar. Esto es especialmente notorio en el caso de la educación primaria y secundaria, donde las nuevas generaciones tendrán la responsabilidad de conocer, incorporar y adaptar a los nuevos tiempos el patrimonio recibido para salvaguardarlo. Dirigiendo nuestra mirada hacia la educación y el futuro no podemos obviar, en el estudio del patrimonio musical, todas aquellas músicas que los jóvenes consumen a diario y que constituyen el grueso de sus preferencias musicales de hoy en día...

\section{Patrimonio frente a producción musical: mitos, realidades e incertidumbres}

Algunas investigaciones llevadas a cabo en alumnado de secundaria confirman que las músicas «populares-urbanas» son el conjunto de estilos musicales preferidos por los adolescentes. Por ejemplo, Según Herrera, Cremades y Lorenzo (2010), los jóvenes escuchan de forma mayoritaria aquellos estilos musicales más presentes en los medios. Afirmación vigente, como atestigua la investigación de Faure (2019), centrada en el área urbana de Barcelona, donde los resultados confirman el pop, el reggaetón, el hip-hop, el trap y la música electrónica como los estilos musicales 
más consumidos por los adolescentes de la capital catalana. Pero ¿qué significa la discutida etiqueta de músicas populares-urbanas? ¿Cómo son dichas músicas y qué elementos comunes comparten?

Según Roger Pouivet (2010), para ser caracterizado como «populan un arte debe cumplir dos condiciones: ser accesible económicamente —en cuanto a propiedad privada para el consumo individual- y cognitivamente, es decir, que su asimilación o comprensión no exijan un bagaje cultural extenso o demasiado concreto por parte del oyente. Pero actualmente encontramos un condicionante adicional para su difusión: la gran mayoría de preferencias musicales de los adolescentes han sido creadas por tecnologías de masas. Es decir, medios de producción artística que implican la grabación, duplicación y difusión masiva, no como fijación de una interpretación musical pasajera sobre un soporte físico (o virtual), sino como la construcción, en un estudio de grabación, de un artefacto sonoro original mediante tecnologías del sonido y técnicas de producción muy concretas. En ese contexto, Eisenberg (2005) señala que el término «grabación» resultaría engañoso. Sólo las grabaciones «live» registrarían un evento completo en sí mismo, tal como ha sucedido en un lugar y un momento determinados; las grabaciones de estudio, que conforman la gran mayoría de las músicas populares-urbanas, no sólo fijan un suceso único. Ensambladas a partir de elementos de eventos reales diversos - sean humanos, mecánicos o virtuales-, componen un evento ideal nuevo (Eisenberg, 2005).

Por todo ello, consideramos a las grabaciones como procesos creativos complejos de los que derivan obras fonográficas únicas que serán duplicadas y consumidas de manera idéntica, sin necesidad de una interpretación o ejecución posterior. En este sentido, dichos «artefactos-grabaciones» se asemejan más a las obras pictóricas o fotográficas que a las partituras de un compositor, incluso podríamos considerarlos una forma propia de arte, una práctica de composición, un lenguaje poético (Zak III, 2001). Debemos considerar las músicas populares consumidas por los jóvenes de hoy y constituidas por grabaciones como «músicas de masas», lo que las convierte en un verdadero arte de masas (Pouivet, 2010).

El procedimiento mediante el cual se elaboran dichas obras fonográficas se denomina «producción musical», un cúmulo de procesos tecnológico-creativos que, en el marco de las músicas de consumo masivo, están al servicio de la industria discográfica y permiten manipular sonoramente una idea musical para hacerla encajar en un sector del mercado (Burgess, 2014). El productor musical es la persona que intercede entre el músico y el mundo que escucha, administrando el acceso a la tecnología y sirviendo como filtro musical (Milner, 2016). Así, la música producida es modelada y empaquetada para el consumo de masas.

Un ejemplo de la influencia de la producción musical en la creación sonora, 
sería la loudness war -guerra del volumen-, que se dio a mediados del siglo XX, cuando las radios eran las principales vías de difusión musical y buscaban sonar más potentes que sus competidoras para lograr una mayor audiencia. Como la cantidad máxima de decibelios emisibles por radio estaba regulada, se tuvo que recurrir a técnicas de compresión para poder proporcionar mayor sensación de presión sonora (Devine, 2013). Esta práctica acostumbró a una nueva sonoridad comprimida en las grabaciones, que fue adoptada como referente de calidad y profesionalidad. Llegados a la última década del siglo XX, las discográficas pidieron a los estudios de grabación que, en términos coloquiales, «hiciesen sonar sus discos a radio».

Una de las principales consecuencias en la búsqueda de ese sonido hipercomprimido fue adaptarse a los nuevos hábitos de escucha musical. La llegada de la cultura de consumo juvenil y la aparición de los dispositivos móviles contribuyeron a que el espacio sonoro, en el que se escuchaban las músicas, ya no reuniese las condiciones ideales de una sala de estar y pasasen a ser espacios más ruidosos. En dichos entornos, cualquier disminución de intensidad, propia de las variaciones dinámicas en la interpretación de una canción, podía suponer directamente dejar de oírla durante unos instantes. Por lo tanto, la compresión se convirtió en una herramienta necesaria para optimizar la escucha de las grabaciones en esos nuevos espacios de reproducción, a menudo demasiado ruidosos para permitir que hubiera pasajes de baja intensidad sonora (Katz, 2002).

Con el tiempo, nuevas posibilidades de manipulación sonora se han ido sumando a los recursos de producción musical. Por ejemplo, las herramientas de corrección, como el Beat Detective, que logra «cuantizan» o corregir el ritmo de una interpretación mediante la reubicación, en el tiempo, de cada golpe o transitorio, en función de la métrica y la subdivisión deseada. En esta línea, encontramos también el procesador de tono Auto-Tune, un programa que corrige la afinación de la voz y la ajusta a la escala musical deseada y que, hoy en día, se usa en la mayor parte de las producciones de música destinadas a adolescentes (Danielsen, 2017).

Todo ello ha desembocado en las características actuales de las músicas populares de masas. La investigación de Faure (2019) muestra cómo, a día de hoy, la mayoría de canciones consumidas por los adolescentes catalanes comparten, en primer lugar, una gran homogeneidad tímbrica, propia del proceso de moderación sonora al que se someten todas las músicas de consumo masivo, que pretende evitar el rechazo de los oyentes que no estén familiarizados con sonoridades ubicadas en los extremos del espectro en frecuencias; en segundo lugar, un proceso de mecanización o cuantización rítmica que facilita su reproducción encadenada, por ejemplo, en sesiones de baile donde tengan que enlazarse o superponerse varias canciones; y en tercer lugar, un proceso de limitación dinámica que favorezca la reproducción de las canciones de acuerdo con los hábitos de consumo musical 
juvenil como, por ejemplo, escuchar música en lugares ruidosos o mediante dispositivos móviles, etc.

Todo lo expuesto hasta este punto evidencia una fuerte influencia mercantilista de la industria discográfica sobre las características de las músicas populares de consumo masivo. En consecuencia, la deriva sonora de las músicas populares ha acarreado numerosas reacciones adversas. Milner recoge algunas de ellas en su libro El Sonido y la Perfección (2016), como las observaciones de John Cage, quien alertó sobre la ficción que representan los discos y el riesgo de que los conciertos acaben por resultar decepcionantes para los oyentes, acostumbrados a la perfección construida en las grabaciones. En esta misma línea de pensamiento, el compositor Roger Reynolds expresó su preocupación por el distanciamiento entre la experiencia privada de las grabaciones y la experiencia pública de los directos (Milner, 2016).

También, el historiador de la música William Ivey centró su preocupación en el fenómeno de homogeneización provocado el mercado de las grabaciones, ya que se estaban estableciendo estándares de cómo debían sonar los discos y, en consecuencia, cómo debían confeccionarse las músicas. Llegó incluso a afirmar que los oyentes estaban centrando su interés más en las grabaciones en sí mismas que en la música que contenían (Milner, 2016). En el mismo sentido, Jacques Attali (1977) ya alertaba, hace unas décadas, que habíamos dejado atrás la Edad de la Representación, entendida como una época en la que la experiencia musical se organizaba alrededor de la interpretación, para entrar en la Edad de la Repetición, donde son las grabaciones y los procesos industriales que las crean quienes van a definir la música. En el siglo XXI, Schafer (2013) llega aún más lejos y advierte de una especie de patología global, que bautiza como «esquizofonía», que es consecuencia de la escisión entre el sonido original y su transmisión o reproducción electroacústica.

Obviamente, no podemos quedarnos únicamente con las visiones negativas. Si bien es verdad que hace años que se observa una tendencia hacia la homogeneización de las músicas de masas, las posibilidades creativas en constante renovación que nos brindan las tecnologías de la grabación del sonido también auguran un porvenir musical de lo más fructífero y prometedor. Cabe preguntarnos entonces ¿en qué punto situará todo esto a nuestro futuro patrimonio musical popular en Cataluña? ¿Cómo influye este contexto tecnológico a nuestros adolescentes? ¿Qué papel pueden jugar los agentes educativos en todo ello?

\section{Conclusiones}

Hasta aquí algunos hechos y miradas que pretenden describir una situación. Pero queremos ir un paso más allá y atisbar un camino consistente con la riqueza 
que alberga el patrimonio musical popular y tradicional en Cataluña. A pesar de su valor, su dimensión y expansión, estamos ante un hecho frágil per se, un bien que necesita renovarse, elementos que se agotan en sí mismos y para los que debemos imaginar estrategias de conservación y transmisión eficaces en el marco de la educación formal, aunque persiguiendo la pulcritud en su función y uso.

En el contexto en el que nos encontramos, si nos atenemos a un bien irremplazable, hace falta que proliferen a su alrededor propuestas de gestión y, fundamentalmente, de educación para potenciar su protección en manos de la sociedad. Hemos observado cómo la comprensión del patrimonio resulta fundamental para su interpretación y conservación, aunque, quizás, un excesivo intelectualismo podría llegar a desviar el valor completo del patrimonio popular como expresión colectiva, como latido emocional, sobre todo en aquellas tradiciones ya olvidadas o poco conocidas. La necesidad de recrear aspectos que provengan de la reinterpretación de una tradición que dejó de vivir, existir, sonar, realizarse o transmitirse oralmente, quedando sólo documentación escrita no sonora ha derivado en la denominada «folklorización», que adapta la tradición, deformándola por falta o acomodación de datos y conocimientos, para reivindicar una identidad colectiva con valores populares (Martí, 1996).

Sin duda la tradición se reinventa, se adapta y merece que sea así. No en vano inventamos - si hace falta- tradiciones que nos justifiquen y otorguen cierta trascendencia a nuestros actos y creencias (Hobsbawm y Ranger, 1988). El patrimonio musical popular y tradicional en Cataluña, a pesar de los muchos cambios que sufra, persistirá, como el río que seguirá siendo río mientras la corriente renueve sus aguas. De aquí la necesidad de entender la música como una actividad y una experiencia, más allá de como un simple objeto patrimonial. Es por ello que las propuestas educativas, presentes y futuras, deberán atender dichas transformaciones con rigor y cautela. La educación formal deberá esforzarse por encontrar el equilibrio entre preservar las distintas manifestaciones del patrimonio musical del pasado, integrar respetuosamente su deriva presente y favorecer la construcción de un patrimonio futuro en el que todas las piezas de nuestro entramado cultural tengan cabida y gocen de reconocimiento.

Si observamos las sucesivas adaptaciones que se han dado en los currículums de Educación Secundaria en España en las últimas décadas, destaca una tendencia creciente en pro de la inclusión de las músicas populares urbanas (Rodríguez, 2004). Esto ha contribuido a acercar los contenidos de la asignatura de música a la realidad musical de los adolescentes, con un consiguiente favorecimiento de su motivación y aprendizaje (Flores, 2007). Del mismo modo, autores como Powell, Smith, West y Kratus (2019) o Springer (2015) subrayan los amplios beneficios a nivel competencial que el estudio de estas músicas aporta al desarrollo de los jóvenes. Pero, si bien la inclusión creciente de dichas músicas en la educación formal 
supone un éxito, la metodología mediante la cual suelen plantearse en las aulas, quizás aún deba repensarse.

Atendiendo a Flores (2007), las músicas populares urbanas se producen mediante unos procedimientos creativos propios, mientras que las metodologías pedagógicas en la educación musical formal aún se rigen por patrones característicos de otras músicas - véase la música culta o la tradicional-. Es por ello que nuestra primera propuesta educativa se centra en el acercamiento de las prácticas propias y genuinas de las músicas populares urbanas a las aulas de Secundaria, mediante la introducción de las tecnologías de grabación y las técnicas de producción musical en los currículos; una tarea pendiente y necesaria para ayudar a los jóvenes a comprender y desarrollar una mirada crítica hacia su propia realidad musical (Wise, Greenwood y Davis (2011). Además, atendiendo a Galera (2011), las tecnologías de grabación de sonido estimulan la creatividad y potencian la cooperación entre el alumnado, favoreciendo la adquisición de competencias auditivas (Baker y Green, 2013).

Aun así, una buena formación musical no puede limitarse a una sola categoría de músicas. Ceñirse exclusivamente a los géneros más populares entre los adolescentes, pondría en peligro la delicada situación de nuestro patrimonio musical popular. Por este motivo, y de acuerdo con McPhail (2013), abogamos a favor de complementar dichas enseñanzas con el mantenimiento de la tradición pedagógica musical heredada.

La dicotomía entre el consumir música y realizarla está presente, como la realidad misma de los adolescentes y su relación con la música, gracias a múltiples manifestaciones populares en las que participan. En el contexto de la Cataluña actual, queremos destacar: la glosa o canción improvisada en el aula (Martí, 2011; Bataller, 2013; Casals, 2017); la cobla de ministrers de Olot y su difusión en toda su comarca; la Banda Provençana del Centre de les Arts de Hospitalet de Llobregat, creada a imagen de los proyectos tándem (Gustems y Calderón, 2016); els balls de bastons como talleres del Esbart Català de Dansaires, para familiarizarse con la danza popular activa (Esbart Català de Dansaires, 2020); y la experiencia de Aprendizaje-Servicio Tocant el cel amb la mà, centrada en la participación musical en el mundo casteller.

Consumir un tipo, estilo o género de música no está reñido con el realizar otro tipo, estilo o género de música. Es tarea de los docentes utilizar el patrimonio cultural popular como contrapropuesta a la cultura de masas para que, desde su propia manifestación viva, no sólo en el instituto sino con su realización en el contexto, proporcione la satisfacción colectiva y de cohesión social entre todos sus copartícipes desarrollando, además de la dimensión sociocultural, la dimensión personal e interpersonal, provocado por el formar parte de un proyecto cultural que traspasa los muros del instituto y se proyecta en la sociedad. 
Las actividades de cultura popular planteadas para la educación secundaria obligatoria se relacionan directamente con competencias propias del ámbito social y artístico, permitiendo, gracias a su carácter interdisciplinar, desarrollar competencias de otros ámbitos, como el de la lingüística, educación física, y cultura y valores, así como de tipo transversal, generando interconexiones en trabajos de síntesis y proyectos de investigación ${ }^{1}$, y propiciando el uso de metodologías de enseñanza y aprendizaje relacionadas con la sociedad, como son las de aprendizajeservicio $^{2}$ (VVAA, 2018).

La experiencia de la vivencia patrimonial musical resulta clave tanto en el proceso de preservación como en el proceso de transformación. Aprovechar el amplio legado presente en nuestras calles y plazas, pueblos y ciudades, para traerlo a las aulas de alumnado adolescente de educación musical, reflexivamente pero vívidamente para su participación, es la piedra angular que permite pensar que el patrimonio cultural popular en Cataluña y, por extensión, en cualquier sociedad occidental, no es sólo una forma de ver el pasado, sino también una forma de vivir el presente para encarar el futuro.

\section{Agradecimientos}

Este trabajo es resultado indirecto de dos tesis doctorales de sus autores, que manifiestan no tener ningún tipo de conflicto de intereses.

\section{Referencias}

Arnella, J. (Coord.). (1994). Luthiers i instruments tradicionals de Catalunya. Calella: Ajuntament de Calella.

Asociación para la Interpretación del Patrimonio. (2006). Recomendaciones para las Buenas Prácticas en Interpretación del Patrimonio Natural y Cultural. Sevilla: AIP.

Attali, J. (1977). Bruits. París: PUF.

1 El denominado "trabajo de síntesis" o "proyecto de investigación" es una actividad docente obligatoria en la educación secundaria en Cataluña sobre un tema libre elegido por cada alumno, y donde este aplica sus conocimientos y competencias transversales adquiridas a lo largo de esta etapa educativa.

2 El Aprendizaje-Servicio es una modalidad docente instaurada sobre todo en espacios educativos no formales, basada en el voluntariado de los docentes aplicado a colectivos con necesidades poco cubiertas por el sistema educativo formal. Se entiende que el servicio efectuado permite también determinados aprendizajes de tipo práctico y formativo, por su capacidad emocional y experiencial. 
Baker, D., y Green, L. (2013). Ear playing and aural development in the instrumental lesson: Results from a "case-control" experiment. International Journal of Music Education, 35(2), 141-159. https://doi.org/10.1177/1321103X13508254

Bartok, B. (1979). Escritos sobre música popular. México: Siglo XXI editores.

Bataller, A. (2013). La literatura de transmisión oral en la ESO. Tantágora. Revista de literatura oral, 15, 1-5. http://hdl.handle.net/10550/34915

Burgess, R. J. (2014). The history of music production. Oxford: Oxford University Press.

Carreras, G., y Garcia Petit, L. (2018). El patrimoni Cultural Inmaterial. Què és? Canemàs, Revista de Pensament Associatiu, 15, 180-184. https://www.ens.cat/assets/PDF/canemas/Canemas_15.pdf

Casals, A. (2017). La cançó improvisada en la cruilla sobre el sentit de la tradició a l'escola. Caramella: revista de música i cultura popular, 37, 20-23. https://grupsderecerca. uab.cat/musicaieducacio/node/261

Crivillé, J. (1983). Historia de la música española. 7 El folkelore musical. Madrid: Alianza Música.

Danielsen, A. (2017). Music, media and technological creativity in the digital age. Nordic Research in Music Education, 18, 9-22. http:/ / hdl.handle.net/11250/2490532

Dart, T. (2002). La interpretación de la música. Madrid: A. Machado Libros.

Devine, K. (2013). Imperfect sound forever: Loudness wars, listening formations and the history of sound reproduction. Popular Music, 32(2), 159-176. https://doi. org/10.1017/S0261143013000032

Eisenberg, E. (2005). The Recording Angel, Music, Records and Culture from Aristotle to Zappa. New Haven (CT): Yale University Press.

Esbart Català de Dansaires. (2020). Memòria d'activitats 2019. Barcelona: Esbart Català de Dansaires. http://www.esbartcatala.org/doc/2436/2019\%20Mem\%C3\%B2ria. pdf

Faure, A. (2019). Modelos Sonoros y Preferencias Musicales en la Adolescencia. Un Estudio en el Área Urbana de Barcelona [tesis de doctorado]. Universidad de Barcelona. https://www. tesisenred.net/handle/10803/669946

Faure, A., Calderón, D., y Gustems, J. (2020). Modelos sonoros en la adolescencia: preferencias musicales, identidades e industria discográfica. Musica Hodie, 20, e-63134. https://www.revistas.ufg.br/musica/article/view/63134/35273 
Flores, S. (2007). Principales acercamientos al uso de la música popular actual en la Educación Secundaria. Revista Electrónica de LEEME, 19, 1-16. https:/ /ojs.uv.es/index. $\mathrm{php/LEEME/article/view/9763/9197}$

Galera, M. y Mendoza, J.(2011). Tecnología Musical y Creatividad: Una experiencia en la formación de maestros. Revista electrónica de LEEME, 28, 24-36. https:/ /ojs.uv.es/ index.php/LEEME/article/view/9828/9251

Giráldez, A. (1997). Educación musical desde una perspectiva multicultural: diversas aproximaciones. Trans: Revista Transcultural de Música, 1, 1-13. https://pdfs. semanticscholar.org/5c68/ad341515a1d0965ecfbdd744184502056772.pdf?_ ga $=2.56473896 .289293439 .1587837914-324094943.1586863818$

Gustems, J., Calderón, C., Oporto, M., y Ferreira, E. (2018). La música en el universo de los símbolos. En J. Gustems (ed.) Música y Símbolo (pp. 11-19). Barcelona: Dinsic.

Gustems, J., y Calderón, D. (2016). Proyectos musicales, ciudadania y desarrollo humano: una mirada desde la psicologia positiva. Cuadernos de música, artes visuales y artes escénicas, 11(2), 251-271. https://revistas.javeriana.edu.co/index.php/cma/article/download/12748/Art $\% 2014$

Ham, S. (2007). ¿Puede la Interpretación marcar una diferencia? Respuestas a cuatro preguntas de psicología cognitiva y del comportamiento. Boletín de Interpretación, 17, 10-16. https://boletin.interpretaciondelpatrimonio.com/index.php/boletin/article/ view/165/165

Herrera, L., Cremades, R., y Lorenzo, O. (2010). Preferencias musicales de los estudiantes de Educación Secundaria Obligatoria: influencia de la educación formal e informal. Cultura y Educación, 22, 1, 37-51. https://doi.org/10.1174/113564010790935222

Hobsbawm, E., y Ranger, T. (1988). L'invent de la tradició. Vic: Eumo.

Katz, R. A. (2002). La masterización de audio. El arte y la ciencia. Andoain: Escuela de cine y video.

Kivy, P. (2005). Nuevos ensayos sobre la comprensión musical. Barcelona: Paidós.

Mantel, G. (2010). Interpretación. Del texto al sonido. Madrid: Alianza Música.

Martí i Pérez, J. (1996). El folklorismo. Uso y abuso de la tradición. Barcelona: Ronsel.

Martí, A. (2011). La wiki del projecte Patrimoni cultural: la poesia oral improvisada. Quaderns digitals: Revista de Nuevas Tecnologias y Sociedad, 68, 9. https://dialnet.unirioja. es/servlet/articulo?codigo $=7514101$

Martín, C. (2009). Los centros de Interpretación: urgencia o moda. HER \& MUS, Heritage \& Museography, 1, 50-59. https://www.raco.cat/index.php/Hermus/article/ view/314655 
McPhail, G. (2013). The canon or the kids. Teachers and the recontextualisation of classical and popular music in the secondary school curriculum. International Journal of Music Education, 35(1), 7-20. https://doi.org/10.1177/1321103X13483083

Milner, G. (2016). El Sonido y la Perfección, una historia de la música grabada. Madrid: Lovemonk/Léeme Libros.

Ministerio de Educación, Cultura y Deporte (2015). Real Decreto 1105/2014, de 26 de diciembre, por el que se establece el currículo básico de la Educación Secundaria Obligatoria y del Bachillerato. BOE (03/01/2015), 3, referencia 37, 169-546.

Pedrero, L. M., Barrios, A. y Medina, V. (2019). Adolescentes, smartphones y consumo de audio digital en la era de Spotify. Comunicar. Revista Cientifica de Educomunicación, 27(60), 103-112. https://doi.org/10.3916/C60-2019-10

Peláez, I. (2014). L'Escola Folk del Pirineu: un centre estable d'ensenyament de la música i dansa tradicionals. El patrimoni festiu del Pirineu: 10es Trobades culturals pirinenques, 139146. https://doi.org/10.2436/15.0110.19.18

Pouivet, R. (2010). Philosophie du Rock; Une ontologie des artefacts et des enregistrements. París: Presses Universitaires de France.

Powell, B., Smith, G. D., West, C., y Kratus, J. (2019). Popular Music Education: A Call to Action. Music Educators Journal, 106(1), 21-24. https://doi. org/10.1177/0027432119861528

Pujol i Subirà, M. A. (2017). L'ensenyament i l'aprenentatge de la música tradicional i popular a Catalunya: una anàlisi pedagògica i psicosocial [tesis de doctorado, Universidad de Barcelona]. Tesis doctorals en xarxa. http://hdl.handle.net/10803/405807

Rodríguez, C.X. (2004). Bridging the gap. Popular music and music education. Reston: MENC.

Santacana, J., y Llonch, N. (2016). El patrimonio cultural inmaterialy su didáctica. Gijón: Trea.

Schafer, R. M. (2013). Elpaisaje sonoro y la afinación del mundo. Barcelona: Intermedio.

Springer, D.G. (2015). Teaching popular music: Investigating music educators' perceptions and preparation. International Journal of Music Education, 34(4), 403-415. https:// doi.org/10.1177/0255761415619068

Tilden, F. (2006). La interpretación de nuestro patrimonio. Sevilla: Asociación para la Interpretación del Patrimonio.

UNESCO. (2003). Aplicación de la convención para la salvaguarda del patrimonio. https://ich. unesco.org/doc/src/01853-ES.pdf 
UNESCO. (2020). Intangible Cultural Heritage. https://ich.unesco.org/en/lists

VVAA. (2018). Educació i Cultura Popular. Conclusions i experiències del Fòrum d’Educació i Cultura Popular. Barcelona: Generalitat de Catalunya i Ajuntament de Barcelona.

Wise, S., Greenwood, J., y Davis, N. (2011). Teachers' use of digital technology in secondary music education: Illustrations of changing classrooms. British Journal of Music Education, 28(2), 117-134. https://doi.org/10.1017/S0265051711000039

Zak III, A. (2001). The Poetics of Rock. Berkeley: The University of California Press. 